\title{
Global Stock Market Interdependencies and long-term Portfolio Diversification
}

\author{
Brian M Lucey * \\ Trinity College Dublin
}

\author{
Cal B Muckley \# \\ University College Dublin
}

\begin{abstract}
In this paper, we examine the scope for international stock portfolio diversification, from the viewpoint of a United States representative investor, in regard to both the Asian and the European stock markets. Our findings indicate that despite correlation style evidence to the contrary, the European stock markets provide a superior long-term diversification opportunity relative to that provided by the Asian stock markets. Hence, a short-term measurement of interdependence appears to be uninformative with respect to the diversification opportunities of investors with long-term investment horizons. In terms of methodology, we adopt common stochastic trend tests, including a common stochastic trend test which accounts for generalised autoregressive conditional heteroskedasticity effects in conjunction with the recursive estimation of these tests to estimate the development of long-term stock market interdependence linkages. Recursively estimated robust correlations between the international stock markets are utilised to reveal the nature of short-term stock market interdependence linkages.
\end{abstract}

Keywords: Stock Market Linkages, Portfolio Diversification, Correlation, Cointegration, JEL Classification: F3, G1

\# E-mail: cal.muckley@ucd.ie.

* E-mail: blucey@tcd.ie. Corresponding author : Prof. Brian Lucey, Trinity College, Dublin, College

Green, Dublin 2; tel. +353 18961552 . 


\section{Introduction}

Do global stock market correlations, from the viewpoint of an investor with a long-term investment horizon, calibrate the scope for international stock portfolio diversification? In particular, in this article, we empirically investigate, from a long-term perspective, the measurement of interdependence adopted in the classical mean-variance portfolio allocation framework (Markowitz, 1952a, 1952b, 1987).

Salient shortcomings of the classical mean-variance portfolio allocation framework are described in the literature. These shortcomings include the prospect of neglected estimation error with regard to the expected returns and correlations (Scherer, 2002, and Garlappi et al., 2007), the apparent long-term instability of the correlations among global stock markets over time (Longin and Solnik, 1995, Bekaert and Harvey, 2000, Goetzmann et al., 2005, Kim et al., 2005 and Engle et al., 2006), the presence of inescapable transaction costs (commissions, fees, bid-ask-spreads and taxes) and turnover constraints as a result of the likelihood of illiquidity arising in the markets as well as the associated possibility of a costly price impact of trades (Amihud, 2002, and Acharya and Pedersen, 2005). Notwithstanding the provision in this literature of valuable (albeit partial) solutions to these shortcomings, it is generally evident that the more extended the investor's investment time horizon, the more severe the deleterious implications of the outlined shortcomings inherent to the mean-variance portfolio allocation framework. As a result, it may be the case, in regard to an investor with a relatively long-term investment horizon, that an alternative measurement of interdependence should be adopted which is expected to necessitate fewer opportunities to rebalance the investor's stock portfolio with a view to availing of the potential for international stock market diversification.

Time varying volatility effects further accentuate the dilemma of estimation error with respect to the estimation of the main features of the classical mean-variance portfolio allocation framework. Specifically, it is well established, at least since Forbes and Rigobon (2002), that failure to take account of the time-varying nature of the covariance structure of a system of traded securities may lead to significant biases in estimated and interpreted correlation style results. To overcome this impasse a number of approaches have been developed in the extant literature. First, Forbes and Rigobon (2002) provide an estimate of unconditional correlation corrected for time varying 
volatility effects. Second, a substantial body of literature has used various autoregressive conditional heteroskedasticity (henceforth $\mathrm{ARCH}$ ) models such as the Dynamic Conditional Correlation (Engle and Sheppard 2001) approach to estimate directly the dynamics of the correlation process across time. For example, Hardouvelis et al., (2006) in regard to European stock markets and Hyde et al., (2007) in regard to Asian stock markets have extracted time varying correlations which explicitly model the structure of the correlation and covariance matrix at each point in time. Notwithstanding these approaches to resolving the phenomenon of a time-varying covariance structure in respect to the estimation of correlations, there remain the outlined shortcomings with respect to the validity of correlations as a calibration of the global scope for portfolio diversification, particularly over relatively long-term time horizons. As a result, a set of papers in the literature has adopted alternative models of common stochastic trends to capture long-term interdependence linkages between international stock markets.

While a significant body of papers has documented the nature of long-term relations in both Asian (Yang and Siregar 2001, Azman-Saini 2002, Manning (2002) and Phylaktis and Ravazollo, 2005) and European (Serletis and King 1997, Chan et al., 1997, Rangvid, 2001, Voronkova, 2004, Yang et al., 2006 and Aggarwal et al., 2009) stock markets only a few recent contributions have adopted techniques that control for alterations in regime and time varying volatility effects. For example, Lucey and Voronkova (2008) allow for regime switching in cointegrating relationships (i.e. common stochastic trends) for Russian and European stock markets and Lagoarde-Segot and Lucey (2007) examine Middle East and North African stock markets and use, in addition to a regime switching cointegration methodology, the nonparametric cointegration model of Breitung (2002) and the stochastic volatility cointegration model of Harris et al., (2002).

In fact, it is clear that the literature in the area of testing for common stochastic trends, in the context of $\mathrm{ARCH}$ style disturbances, is in its infancy. The theoretical literature (Lee and Tse (1996), Silvapulle and Podivinsky (2000) and Hoglund and Ostermark (2003)) indicates that these non-spherical disturbances aggrandise the size of the Johansen (1988) cointegration test. For example, Lee and Tse (1996) report that while the Johansen (1988) cointegration test tends to overreject the null hypothesis of no cointegration in favour of finding cointegration, the problem is generally not harmful. 
Silvapulle and Podivinsky (2000) report results that are similar. In contrast, Hoglund and Ostermark (2003) find that the eigenvalues of the long-term information matrix for the Johansen (1988) cointegration test are highly sensitive to conditional heteroskedasticity and that therefore this multivariate statistic is only reliable in the context of homoskedastic processes. This latter finding, regarding the size of the cointegration test, becomes increasingly pronounced the more integrated the $\mathrm{ARCH}$ process considered. That said, these contributions pertain to low dimensional systems and, as a result, are of limited empirical relevance. In contrast, empirical contributions (Alexakis and Apergis (1996), Gannon (1996) and Pan et al., (1999)), across a wider range of system dimensions, tend to indicate that these $\mathrm{ARCH}$ effects and their variants exert a significant and deleterious impact on the statistical test's power properties. Specifically, the aforementioned empirical literature identifies significant gains in statistical power once ARCH effects are controlled, when testing for cointegration, using the Johansen (1988) technique.

It is in the spirit of this latter set of papers, which aims to control for heteroskedasticity when testing for common stochastic trends that we work. In particular, this paper examines three interrelated issues: first the extent to which intra-group predominant Asian (Hong Kong, Japan, Korea, Singapore and Taiwan) and European (France, Germany, Italy, the United Kingdom and Sweden) stock markets are statistically interdependent, during the period 1988 through to $2007^{1}$. These groups are also extended to include the United States stock market ${ }^{2}$. Statistical interdependence is estimated from both short- and long-term vantage points. Second, the time varying dynamics and alterations in regime of these interdependence linkages are examined by means of recursive methodologies. Third, the extent to which conventional measurements, of short- and long-term interdependence, are susceptible to the detection of "spurious" interdependence as a consequence of inadequate test specification, in particular in how they account for heteroskedasticity, is addressed in this article. We provide methodological novelty in particular in the latter, estimating a recent test for common

\footnotetext{
1 This period starts after the global financial crisis of 1987 and ends before the advent of the global financial crisis in 2008. Thus, it is the longest recent period that is uncontaminated by the largest rapid adjustments in stock markets' value in recent decades.

2 These markets were selected on the criterion of average market capitalisation in United States dollars during the approximate twenty year period (depending on data availability) prior to December 2007.
} 
stochastic trends under the assumption of ARCH style disturbances. This test, following Gannon (1996) and Aggarwal and Muckley (2010), developed in the framework of the Johansen (1988) cointegration statistic, permits the evaluation of the nature of interdependence while correcting for $\mathrm{ARCH}$ style disturbances. We demonstrate how and when the traditional Johansen (1988) and the new modified test statistic show divergent evolutions of interdependence. In addition, we estimate the correlations - the short-term interdependencies - in a manner, following Forbes and Rigobon 2002, which seeks to control for heteroskedasticity.

Compared to previous literature, our contribution is threefold. First, we find that the set of important European stock markets exhibits a significantly larger correlation with the United States stock market than exhibited by the group of important Asian stock markets. Moreover, our findings indicate that this discrepancy is growing slightly over time. Second, in contrast to the evidence provided by our examination of the continental stock market correlations, the long-term relations appear to bind the Asian stock markets and the United States stock market, while these long-term relations are largely absent between the European stock markets and the United States stock market. Third, following from these outlined contributions, our findings indicate that the popular and traditional co-movement measurement (i.e. the correlation measurement) is uninformative with respect to the diversification decisions of a representative United States investor with a long-term investment horizon.

The remainder of this article is organised as follows: Section II describes the econometric methodologies adopted in this article to model interdependence linkages between the Asian and European stock markets and the United States stock market. Section III describes our data and presents the main finding from our estimation work. Finally, concluding remarks are presented in Section IV.

\section{Correlation and Cointegration Modelling}

In this Section, we outline a specification for the estimation of robust correlations and a statistical test for the presence of otherwise of cointegration relations. Our purpose is to estimate the static and dynamic short- and long-term interdependencies inter-relating the United States stock market with the Asian and the European stock markets. 
A.

We initially conduct robust correlation estimation over a moving window. The contrasting of correlation coefficients during a stable period and during or after a shock is a popular measurement of altering stock market interdependence. For example, King and Wadhwani (1990) report a rise in stock market correlations between the United States, the United Kingdom and Japan after the United States stock market crash, 1987. Lee and Kim (1993) extend this to 12 major markets and find similar results and Calvo and Reinhart (1996) report a rise in bond and emerging stock market correlations during the Mexican peso crisis. As against these findings, Forbes and Rigobon (2002), demonstrate that the correlations (adjusted for heteroskedasticity) did not significantly increase in the aforesaid settings. In this article we adopt this latter adjustment for heteroskedasticity and in this sense our correlation coefficients are robust.

Following Forbes and Rigobon (2002) heteroskedasticity biases tests for cross market transmission based on correlation coefficients. To illustrate, let $x$ and $y$ represent stock market returns and assume no missing variables and the absence of endogeneity

$$
\begin{aligned}
& y_{t}=\alpha+\beta x_{t}+\varepsilon_{t} \\
& E\left[\varepsilon_{t}\right]=0 \\
& E\left[\varepsilon_{t}^{2}\right]=c<\infty \\
& E\left[x_{t} \varepsilon_{t}\right]=0
\end{aligned}
$$

Turning now to divide the sample of data into two groups predicated on the lower $(l)$ and higher $(h)$ variance of $x$. The $\beta$ estimate is consistent and doesn't vary across groups.

$$
\beta^{h}=\frac{\sigma_{x y}^{h}}{\sigma_{x x}^{h}}=\frac{\sigma_{x y}^{l}}{\sigma_{x x}^{l}}=\beta^{l}
$$




$$
\sigma_{x y}^{h}>\sigma_{x y}^{l}
$$

Note that the increase in the variance of $y$ across groups is less than proportional to the increase in the variance of $x$.

$$
\begin{gathered}
\sigma_{y y}=\beta^{2} \sigma_{x x}+\sigma_{e e} \\
\left(\frac{\sigma_{x x}}{\sigma_{y y}}\right)^{h}>\left(\frac{\sigma_{x x}}{\sigma_{y y}}\right)^{l}
\end{gathered}
$$

Therefore, the estimated correlation between $x$ and $y$ increases when the variance of $x$ increases.

$$
\begin{aligned}
& \rho=\frac{\sigma_{x y}}{\sigma_{x} \sigma_{y}}=\beta \frac{\sigma_{x}}{\sigma_{y}} \\
& \rho^{h}>\rho^{l}
\end{aligned}
$$

Following Forbes and Rigobon (2002), it is straightforward to quantify the extent of the bias arising as a result of heteroskedasticity and hence retrieve an estimate of the robust correlations as outlined in Equations 11, 12 and 13

$$
\begin{aligned}
& \rho^{*}=\rho \sqrt{\frac{1+\delta}{1+\delta \rho^{2}}} \\
& \delta=\frac{\sigma_{x x}^{h}}{\sigma_{x x}^{l}}-1 \\
& \rho=\frac{\rho^{*}}{\left.\sqrt{1+\delta[1-}\left(\rho^{*}\right)^{2}\right]}
\end{aligned}
$$

The conditional correlation coefficient is denoted $\rho^{*}$ while the robust (true) correlation coefficient is denoted $\rho$. The relative increase in the variance of $x$ across the two groups is denoted $\delta$. 
B.

Turning now to the estimation of cointegration relations, we perform we perform the well-known Johansen (1988) cointegration test and we also undertake a modified Johansen (1988) testing procedure with a view to mitigating for the deleterious implications of GARCH effects on the estimation of the rank of the long-term information matrix in a specified vector error correction model (henceforth VECM). This modification of the Johansen (1988) procedure follows Gannon (1996), Pan et al. (1999) and Aggarwal and Muckley (2010). In particular, this modification involves the estimation of common roots in which we account for GARCH effects in the correlating combinations of residuals. Consider the $m$-dimensional VECM:

$$
\begin{aligned}
& \Delta x_{t}=\pi x_{t-1}+\sum_{i=1}^{k-1} \pi_{i} \Delta x_{t-1}+\varepsilon_{t} \\
& \pi=\sum_{i=1}^{k} \pi_{i}-I \\
& \pi_{i}=-\sum_{i+1}^{k} \pi_{j},(i=1, \ldots, k-1)
\end{aligned}
$$

The residuals, $\varepsilon_{t}$, are assumed independent normally distributed $m$-dimensional with mean zero and variance, $\Omega$. The parameters $\left(\pi, \pi_{1}, \ldots, \pi_{k-1}, \Omega\right)$ are unrestricted and are estimated by maximum likelihood estimation. The $x_{t}$ are vectors of series containing the stock market prices. Now, consider two auxiliary equations:

$$
\begin{aligned}
& \Delta x_{t}=\sum_{i=1}^{k-1} \delta_{1 i} \Delta x_{t-1}+r_{0 t} \\
& x_{t-1}=\sum_{i=1}^{k-1} \delta_{2 i} \Delta x_{t-1}+r_{1 t}
\end{aligned}
$$

where $\delta_{1}$ and $\delta_{2}$ are estimated by ordinary least squares (see Johansen and Juselius, 1990). The vectors of series $r_{o t}$ and $r_{l t}$ contain the residuals from the auxiliary regressions. Note that the VECM, Eq. (1) can now be reformulated as a two-stage estimation process:

$$
r_{0 t}=\alpha \beta^{\prime} r_{1 t}+\text { error }
$$

The null hypothesis, $H_{0}$, that the components of $x_{t}$ are cointegrated may be stated as

$$
H_{0}: \pi=\alpha \beta^{\prime}
$$

This implies that $\mathrm{q}=\operatorname{rank}(\pi)<m$. The rows of the $(\mathrm{m} * \mathrm{q})$ matrix $\beta^{\prime}$ are the 
distinct cointegrating vectors of $x_{t}$ i.e., $\beta^{\prime}\left(x_{t}\right)$ are $I(0)$. The elements of $\alpha$ represent the loadings of each of the $r$ cointegrating relations.

The canonical correlations can be estimated from the stacked residuals via Eq. 19 where the weights, $\omega_{1 i} \ldots \omega_{p i}$ and $\kappa_{1 i} \ldots \kappa_{p i}$ are canonical weights

and

$$
\widehat{v}=\widehat{\omega}_{1 i} r_{01 i}+\ldots+\widehat{\omega}_{p i} r_{0 p i}
$$

Where $r$ refers to the residuals from Eq.s (17) and (18) and the subscript $i$ refers to the $i^{\text {th }}$ pair of canonical variates. Therefore these variates $\hat{v}_{i}$ and $\hat{n}_{i}$ have a zero mean.

Finally, estimate $\operatorname{GARCH}(1,1)$ equations for $\widehat{v}_{i}$ and $\widehat{n}_{i}$ for $i=1, \ldots, q$.

$$
\begin{aligned}
& \widehat{v}_{i t}=\rho_{i} \hat{n}_{i t}+u_{i t} \\
& h_{i t}=\operatorname{Var}\left(\widehat{v}_{i t} / \widehat{n}_{i t}\right)=\alpha_{i 0}+\alpha_{i 1} u_{t-1}^{2}+\beta_{i 1} h_{t-1}
\end{aligned}
$$

and compare the t-statistic for $\rho$ with the tabulated values of the statistic given in Mackinnon (1991). Hence, an estimate of each eigenvalue, $\lambda_{i}$, is available $\rho_{i} \approx \sqrt{\lambda_{i}}$. Neglecting GARCH effects provides inefficient estimates of the $\lambda_{i} s$ while allowing for GARCH effects partially accounts for simultaneous volatility effects in the system. If there is common volatility across the series entering the system then linear combinations of the deviations from long-term paths will capture these common factors.

The concern is that in neglecting to account for common volatility shocks, the test statistics may fail to reveal significant common roots. The test statistics are estimated from the procedure described in equations 21, 22, 23 and 24. We perform the two-stage procedure with and without accounting for GARCH effects. The variates are constructed using canonical coefficients as weights. This procedure provides an estimate, robust to GARCH effects, of the number of cointegrating vectors.

\section{Data and Estimation of Interdependencies}

We examine the predominant, in terms of market capitalisation, Asian and European stock markets, namely the Hong Kong, Japan, Korea, Singapore and Taiwan 
markets in Asia and the France, Germany, Italy, United Kingdom, and Sweden markets in Europe, as well as the USA stock market. Each continental region is also examined as a group of markets and this group of markets is extended to include the USA stock market. All data are closing prices denominated in local currency, and these data span the period May 1988 through to December 2007, on a daily frequency, providing 5117 observations. We elect to adopt the local currency numeraire as this serves to disentangle the effects of foreign exchange and stock market dynamics and we wish to identify stock market interdependencies, without the complicating implications of foreign exchange rate variations. All data are Datastream total return indices.

Following from the variety of operating hours and time zones considered, the realisation of daily returns across the international stock markets are not contemporaneous. With a view to addressing this feature of the data the United States data is sampled at time $t$ alongside the European observations, while the Asian rates are observed at time $t+1 .^{3}$

In Table 1 the summary statistics for the stock price levels and their continuously compounded returns are presented. Our measurement of variance is more than twice as large, on average, in respect to the Asian markets than it is with respect to the European markets. Notwithstanding the United Kingdom's stock market, the United States stock market exhibits the smallest variance of the stock markets examined. The Lagrange multiplier test to identify first-order autoregressive conditional heteroskedastic (henceforth $\mathrm{ARCH}$ ) effects finds pronounced $\mathrm{ARCH}$ effects throughout the markets examined. In addition, the summary statistics indicate that the return distributions for the preponderance of stock markets are characterised by higher peakedness and thick tails relative to the normal distribution. The exceptions are the Japanese, Korean and Taiwanese return distributions which appear to be approximately symmetric. Finally, both the Philips and Perron (1988), the Augmented Dickey Fuller (1979) and the Seo (1999) unit root tests indicate the presence of a unit root in the levels of all price series while the continuously compounded returns are stationary.

${ }^{3}$ We acknowledge that residual non-synchronous features of the data would tend to diminish the estimated measurements of interdependence which we obtain. 
In Table 2 the pair-wise unconditional correlation matrices of the Asian and European groupings of stock markets extended to include the United States stock market are presented. The pair-wise correlations appear to be markedly larger among the European stock markets than among the Asian stock markets. Of foremost importance, the arithmetic mean of the pair-wise correlations between the European markets and the United States stock market (0.39) are on average approximately 33 percent larger than the pair-wise correlations between the Asian markets and the United States stock market (0.30). These correlation measurements may, however, be spurious in light of the heteroskedasticity effects revealed in these data. In Figure 1, recursive heteroskedasticity robust results with respect to the pair-wise correlations between the continental regions and the United States (following Forbes and Rigobon 2002) are presented. Overall, it is evident that the size of the difference in the arithmetic mean of the robust pair-wise correlations, across continental regions, has grown in moderately in magnitude since the start of the sample period examined.

[Please insert Table 2 and Figure 1 Here]

We also examine the question of whether there is a long-term relationship binding the behaviour, over time, of each set of stock markets, specifically the Asian and European stock markets, and these groupings extended to include the United States stock market. We approach this question by adopting two methodologies: firstly we use the Johansen (1988) multivariate likelihood ratio cointegration analysis and second we use the Gannon (1996) cointegration test that is a modification of the Johansen (1988) test with a view to controlling for heteroskedasticity. The presence of cointegration indicates there are common forces driving the long-term movements of the corresponding grouping of stock market indices.

Table 2 presents the results from the Johansen (1988) methodology; specifically it presents the trace statistics corresponding to the null hypothesis that there are at most $\gamma$ distinct cointegrating vectors estimated, $\gamma=0,1,2,3$. The critical values are sourced in Osterwald-Lenum (1992). It is apparent that there is only tentative evidence of a single 
cointegrating vector in the set of Asian stock markets even when this set of stock markets is extended to include the United States stock market. In contrast, the set of European stock markets appears to exhibit up to two cointegrating vectors, while this set extended to include the United States stock market exhibits up to three cointegrating vectors. Therefore, according to this methodology, the European and United States stock market system appears to exhibit significantly more evidence of cointegration relations than does the Asian and the United States stock market system.

\section{[Please Insert Table 2 Here]}

As a result of the summary statistics presented in Table 1, which indicate, inter alia, the prevalence of pervasive $\mathrm{ARCH}$ effects across the stock market indices, a modified cointegration test with GARCH effects is performed. Table 4 presents the results. The test statistics are estimated from the procedure described by Eqs 23 and 24. The row of $\rho=1$ gives the test results based on variates constructed from the weights for the maximum canonical correlation, whereas the second highest canonical correlation is used for the row of $\rho=2$, and so forth. In marked contrast to the Johansen's (1988) multivariate likelihood ratio cointegration approach only tentative evidence, at the ten percent significance level, is found of the presence of a single cointegrating vector in the European and United States stock market system while there is evidence of several cointegrating vectors in the Asian stock market system and in this system extended to include the United States stock market.

[Please Insert Table 3 Here]

In the spirit of Hansen and Johansen (1999), Rangvid (2001) and Rangvid and Sorensen (2002) we recursively assess the evolution of the number of cointegrating vectors using a modification of the Johansen (1988) test, provided by Gannon (1996) which accounts for GARCH effects. Prior to discussing the results from these analyses it is important to assert the presence of a unit root in each of the price series in each of the recursively estimated windows of data examined.

Figure 2 presents the results from the recursively performed unit root tests, controlling for GARCH effects (following Seo 1999), on the price and continuously 
compounded return series examined. Overall, it is evident, with respect to the stock market price series examined, that the vast preponderance of unit root tests, irrespective of the window of data concerned, fail to reject the null hypothesis of a unit root. By comparison, the unit root tests on virtually all the continuously compounded return series, irrespective of the window of data concerned, convincingly reject the null hypothesis of a unit root. As a result, we proceed and perform the recursive unit root tests over the range of windows of sample data examined.

[Please Insert Figure 2 Here]

In Figure 3 we provide a graphical presentation of recursively estimated unconditional correlations between the Asian and the European stock markets and the United States stock market, which are robust to heteroskedasticity. The methodology adopted follows Forbes and Rigobon (2002) in mitigating for heteroskedasticity. In totality, the findings indicate that the European stock market returns exhibit moderately larger robust recursive unconditional correlations with the United States stock market returns (mean unconditional robust correlation is 0.25) than do the Asian stock market returns (mean unconditional robust correlation correlation is 0.20). Furthermore, it is evident that the size of the difference in the arithmetic mean of the pair-wise unconditional robust correlations, across continental regions, has grown in magnitude over the period studied.

[Please Insert Figure 3 Here]

We turn now to the evolution of the number of cointegrating vectors. Our rationale is outlined as follows: over time, relatively more cointegration vectors and thus relatively fewer 'common' stochastic trends implies the increasing stationarity of the relevant systems of time series or equivalently the relevant systems of time series being increasingly driven by the same shocks with permanent effects. If all time series actually remain non-stationary (as approximately validated in Figure 2) during the period where the number of common stochastic trends declines, the non-stationarity is necessarily 
caused by fewer shocks with a permanent effect. In the context of our recursive analyses, we examine the hypothesis of no cointegrating vectors against a general alternative.

[Please Insert Figure 4 Here]

In Figures 4 is presented the graphical representations of the recursive statistics, from both the Johansen (1988) methodology and the Gannon (1996) GARCH modified econometric methodology to test for the null hypothesis of no cointegration. The results are rescaled at the $90 \%$ critical value to equal 1 to facilitate interpretation. According to the Johansen (1988) test the set of Asian markets exhibits significant evidence of cointegration prior to 2000, while significant evidence of a lack of cointegration is present subsequent to this period. A similar picture emerges when the Asian markets are examined in conjunction with the United States stock market. By comparison, however, once the Gannon (1996) modification is performed, it is apparent that, notwithstanding several brief periods, these systems of stock market indices are cointegrated throughout the sample examined. Turning now to the European system of stock market indices, according to the Johansen (1988) test, there is significant evidence of cointegration throughout the sample examined and this evidence is strengthened with the inclusion of the United States stock market in the system. By comparison, however, once the Gannon (1996) modification is performed, there is a compelling absence of evidence of cointegration relations, even once the United States stock market has been included in the stock market system.

Taken together, the results indicate that the Asian region's stock markets and this region's markets extended to include the stock market of the United States exhibits a significant robust cointegration relation in contrast to the results presented regarding the European markets, even with the grouping of European stock markets extended to include the United States stock market.

\section{4: Conclusion}

The overall aim of this article is to investigate the level and evolution of 
interdependence linkages between the United States stock market and the important Asian and European stock markets. Ultimately, we are specifically concerned with both short-term dissipative measurements of interdependence alongside measurements of long-term statistical equilibria, from a common stochastic trends vantage point. Our motivation stems from the implications of our findings for the literatures on portfolio diversification, particularly in the context of a representative United States investor with a long-term investment horizon. An important methodological feature of our work is that we consider the spurious consequences that time varying volatility appears to impart on our measurements of interdependence and we control for these effects.

Our findings indicate that measurements of the dissipative short-term correlations and the long-term interdependencies, between Asian and European stock markets and the United States stock market, tell markedly different stories. In particular, short-term comovements are small amongst the Asian stock markets relative to the United States stock market in contrast with the short term co-movements of the European markets with the United States stock market, which are relatively large. Against this, long-term relations are present between the Asian stock markets and the United States stock market while these long-term relations are generally absent between the European stock markets and the United States stock market. In conclusion, it is evident that the traditional comovement measurement (i.e. the correlation statistic) is uninformative with respect to the stock portfolio diversification decision of a representative United States investor with a long-term investment horizon. Indeed, such a representative United States investor is expected to benefit from an examination of common stochastic trends rather than exclusively relying on measurements of correlation. These findings clearly have important practical implications for scholars and investors interested in international stock portfolio diversification. 


\section{References}

Aggarwal, R., Lucey, B., and C. Muckley (2010), 'Dynamics of Stock Market Integration in Europe: Impact of Political Economy Events.' Journal of Common Market Studies, 48(3), pp. 641-660.

Aggarwal, R and C. Muckley (2010) 'Assessing Co-ordinated Asian Exchange Rate Regimes.' Journal of International Financial Markets Institutions and Money (2010) 20(2): 149-165.

Alexakis, P. and N. Apergis (1996), 'ARCH effects and cointegration: Is the foreign exchange market efficient?' Journal of Banking and Finance, 20, pp. 687-697.

Amihud, Y. (2002), 'Illiquidity and stock returns: cross-section and time-series effects.' Journal of Financial Markets, 5, pp. 31-56.

Acharya V. and L.H. Pedersen (2005), 'Asset pricing with liquidity risk.' Journal of Financial Economics, 77, pp. 375410 .

Azman-Saini, W.N.W., Azali, M., Habibullah., M.S. and K.G. Matthews (2002), 'Financial Integration and the ASEAN-5 stock markets.' Applied Economics, 34, pp. 2283-2288.

Bekaert, G. and C. Harvey (2000), 'Capital Flows and the Behaviour of Emerging Stock Market Stock Returns.' . In: Edwards, S.

(Ed.), Capital Inflows to Emerging Markets. NBER and University of Chicago Press, pp. 159-194.

Bredin, D. and C. Muckley (2011), 'An Emerging Equilibrium in the EU Emissions Trading Scheme.' Energy Economics, forthcoming.

Breitung, J. (2002). 'Nonparametric Tests for Unit Roots and Cointegration.' Journal of Econometrics, 108(2), pp. 343363.

Calvo, Sarah, and Carmen M. Reinhart, 1996, Capital flows to Latin America: Is there evidence of contagion effects? in Guillermo A. Calvo, Morris Goldstein, and Eduard Hochreiter, eds.: Private Capital Flows to Emerging Markets After the Mexican Crisis (Institute for Inter-national Economics, Washington, DC).

Chan K.C., Gup, E.B. and M.S. Pan (1997), 'International Stock Market Efficiency and Integration: A Study of Eighteen Nations.' Journal of Business, Finance and Accounting, 24(6), pp. 803-830.

Dickey, D. and W.A. Fuller (1979), 'Distribution of the Estimates for Autoregressive Time Series with a Unit Root.' Journal of the American Statistical Association, 74, pp. 427-431.

Engle, R.F. and K. Sheppard (2001), 'Theoretical and Empirical Properties of Dynamic Conditional Correlation Multivariate GARCH.' Working Paper No. 2001-15, University of California San Diego.

Engle, R.F., L. Capiello and K. Sheppard (2006), 'Asymmetric Dynamics in the Correlations of Global Stock and Bond Returns.' Oxford University Press, vol. 4(4), pp. 537-572.

Forbes, K, Rigobon, R. (2002), 'No Contagion, Only Interdependence: Measuring Stock Market Co-Movements.' Journal of Finance, 57, 5, pp. 2223-2261.

Gannon, G. (1996), 'First and second order inefficiency in Australasian currency markets.' Pacific-Basin Finance Journal 4, pp. 315-327.

Garlappi, L., R. Uppal and T. Wang (2007), 'Portfolio Selection with Parameter and Model Uncertainty: A Multi-Prior Approach.' Review of Financial Studies, 20(1).

Goetzmann, W., Rouwenhurst , G.,and L. Lingfeng (2005), 'Longer Term Global Market Correlations.' Journal of Business 78, pp. 1-38.

Hardouvelis, G., Malliaropulos D, and R. Priestley (2006), 'EMU and European Stock Market Integration.' Journal of Business, 79(1). 365-92. 
Harris, D., B. McCabe, and S. Leybourne. (2002), 'Stochastic Cointegration: Estimation and Inference.' Journal of Econometrics, 111(2), pp. 363-384.

Hoglund, R. and R. Ostermark (2003), 'Size and power of some cointegration tests under structural breaks and heteroskedastic noise.' Statistical Papers, 44, pp. 1-22.

Hyde, S., Bredin, D., Nguyen, N. (2007), 'Correlation dynamics between Asia-Pacific, EU and US stock returns.' International Finance Review, 7, pp. 39-61.

Johansen, S.,(1988), 'Statistical Analysis of Cointegrating Vectors.' Journal of Economic Dynamics and Control, 12, pp. 231-254.

King, Mervyn A., and Sushil Wadhwani, (1990), 'Transmission of volatility between stock markets', Review of Financial Studies 3, 5-33.

Kim, s.-J., F. Moshirian and E. Wu (2005), 'Dynamic Stock Market Integration Driven by the European Monetary Union.' Journal of Banking and Finance, 29(10, pp. 2475-502.

Lagoarde-Segot, T., and B.M. Lucey (2007), 'Capital market integration in the Middle East and North Africa.' Emerging Markets Finance and Trade, 43 (3), pp. 34-57.

Lee, Sang B., and Kwang Jung Kim, 1993, Does the October 1987 crash strengthen the co-movements among national stock markets? Review of Financial Economics 3, 89-102.

Lee, T.H. and Y. Tse (1996), 'Cointegration tests with Conditional Heteroskedasticity.' Journal of Econometrics, 73, pp. 401-410.

Longin, F., and B. Solnik (1995), 'Is the Correlation in International Stock Returns Constant: 1960-1990?' Journal of International Money and Finance, 14, pp 3-26.

Lucey, B.M. and S. Voronkova (2008), 'Russian stock market linkages before and after the 1998 crisis: Evidence from stochastic and regime-switching cointegration tests.' Journal of International Money and Finance, 27 (8), pp. 13031324.

Manning, Neil, (2002), 'Common Trends and Convergence? South East Asian Equity Markets, 1988-1999.' Journal of International Money and Finance, 21, 183-202.

Markowitz, H.M. (1952a), 'Portfolio Selection.' Journal of Finance, 7, pp. 77-91.

Markowitz, H.M. (1952b), 'The utility of wealth.’ Journal of Political Economy, 60, pp. 151-158.

Markowitz, H.M. (1987), 'Mean-Variance Analysis in Portfolio Choice and Capital Markets.' Basil Blackwell, Oxford, United Kingdom.

Pan M.S., Liu Y.A., Roth H.J., (1999). 'Common stochastic trends and volatility in Asian-Pacific stock markets.' Global Finance Journal 10, 2, pp. 161-172.

Phillips, Peter, and Pierre Perron (1988), ‘Testing for a Unit Root in Time Series Regression.’ Biometrica, 75, pp. 335346.

Phylaktis K., and F. Ravazzolo (2005), 'Stock Market Linkages in Emerging Markets: Implications for International Portfolio Diversification,' Journal of International Financial Markets Institutions and Money, 15(2), pp. 91-106.

Rangvid, J. (2001), 'Increasing Convergence among European Stock Markets? A Recursive Common Stochastic Trends Analysis.' Economic Letters, 71, pp. 383-89.

Silvapulle, P. and J.M. Podivinsky (2000), 'The Effect of Non-Normal Disturbances and Conditional Heteroskedasticity on Multiple Cointegration and Restriction Tests.' Journal of Statistical Computation and Simulation 65, 2, pp. 173-189.

Serletis, A. and M. King (1997), 'Common Stochastic Trends and Convergence of European Union Stock Markets.' Manchester School, 65(1), pp. 44-57. 
Scherer, Bernd. (2002), 'Portfolio Resampling: Review and Critique.' Financial Analysts Journal, November/December, pp. 98-109.

Silvapulle, P. and J.M. Podivinsky, (2000), 'The Effect of Non-Normal Disturbances and Conditional Heteroskedasticity on Multiple Cointegration and Restriction Tests.' Journal of Statistical Computation and Simulation, 65, 2, pp. 173-189.

Yang, T. and R. Siregar (2001), An Empirical Examination of the Stock Market Returns in Selected Asia-Pacific Economies in the Pre- and Post-Financial Reform Period, Institute of Southeast Asian Studies, Economics and Finance, 1, pp. 1-62.

Voronkova, S., (2004), Equity Market Integration in Central European Emerging Markets: A Cointegration Analysis with Shifting Regimes. International Review of Financial Analysis, 13(5), 633-47.

Yang, J., Hsiao, C., Li, Q., and Wang, Z. (2006), 'The emerging market crises and stock market linkages: Further evidence". Journal of Applied Econometrics, 21:727744. 
Table 1: Summary Statistics

\begin{tabular}{|c|c|c|c|c|c|c|c|}
\hline Currency & Variance & Skewness & Exc. Kurtosis & $\mathrm{ARCH}$ & PP Unit Root & ADF Unit Root & $A D F(+G a r c h)$ Unit $R c$ \\
\hline ed States & 0.92 & -0.19 & $4.46 \mathrm{a}$ & $170.59^{a}$ & $-0.26\left[-70.86^{a}\right]$ & $-0.27\left[-70.98^{\mathrm{a}}\right]$ & $-1.21\left[-47.45^{\mathrm{a}}\right]$ \\
\hline \multicolumn{8}{|l|}{ Isian Markets } \\
\hline g Kong & 2.30 & $-1.07^{\mathrm{a}}$ & $23.48^{\mathrm{a}}$ & $107.93^{\mathrm{a}}$ & $2.10\left[-68.97^{\mathrm{a}}\right]$ & $1.87\left[-38.19^{\mathrm{a}}\right]$ & $-0.84\left[-42.06^{a}\right]$ \\
\hline pan & 1.38 & 0.02 & $4.03^{\mathrm{a}}$ & $75.65^{a}$ & $-2.12\left[-65.79^{a}\right]$ & $-2.12\left[-50.76^{a}\right]$ & $-1.45^{\mathrm{c}}\left[-43.38^{\mathrm{a}}\right]$ \\
\hline Corea & 3.55 & 0.08 & $4.25^{\mathrm{a}}$ & $164.80^{\mathrm{a}}$ & $1.35\left[-68.80^{\mathrm{a}}\right]$ & $1.37\left[-68.83^{\mathrm{a}}\right]$ & $1.48^{\mathrm{c}}\left[-47.99^{\mathrm{a}}\right]$ \\
\hline ngapore & 1.22 & $-0.26^{a}$ & $7.53^{\mathrm{a}}$ & $273.49^{a}$ & $1.20\left[-65.31^{\mathrm{a}}\right]$ & $1.13\left[-65.27^{a}\right]$ & $0.39\left[-41.72^{\mathrm{a}}\right]$ \\
\hline aiwan & 3.69 & 0.00 & $2.98^{\mathrm{a}}$ & $180.09^{a}$ & $-1.69\left[-68.59^{a}\right]$ & $-1.69\left[-68.44^{a}\right]$ & $-0.57\left[-46.33^{a}\right]$ \\
\hline \multicolumn{8}{|c|}{ European Markets } \\
\hline & 1.21 & $-0.24^{a}$ & $3.63^{\mathrm{a}}$ & $153.54^{\mathrm{a}}$ & $0.34\left[-68.95^{\mathrm{a}}\right]$ & $0.32\left[-68.98^{\mathrm{a}}\right]$ & $-.053\left[-47.98^{\mathrm{a}}\right]$ \\
\hline many & 1.18 & $-0.69^{a}$ & $7.42^{\mathrm{a}}$ & $132.15^{\mathrm{a}}$ & $0.14\left[-68.42^{\mathrm{a}}\right]$ & $0.13\left[-68.42^{\mathrm{a}}\right]$ & $-0.20\left[-42.73^{a}\right]$ \\
\hline aly & 1.41 & $-0.24^{a}$ & $3.59^{\mathrm{a}}$ & $193.62^{\mathrm{a}}$ & $-0.10\left[-68.02^{a}\right]$ & $-0.06\left[-67.93^{a}\right]$ & $-0.54\left[-43.89^{a}\right]$ \\
\hline weden & 0.93 & $-0.59^{\mathrm{a}}$ & $7.49^{\mathrm{a}}$ & $228.65^{\mathrm{a}}$ & $-0.02\left[-69.47^{\mathrm{a}}\right]$ & $-0.04\left[-68.45^{\mathrm{a}}\right]$ & $-2.24^{b}\left[-41.9^{a}\right]$ \\
\hline Inited Kingdom & 0.82 & $-0.22^{a}$ & $3.37^{\mathrm{a}}$ & $252.07^{a}$ & $0.10\left[-69.72^{\mathrm{a}}\right]$ & $0.04\left[-69.73^{\mathrm{a}}\right]$ & $-0.59\left[-48.88^{a}\right]$ \\
\hline
\end{tabular}

Notes. The Table contains summary statistics concerning the examined Asian, European and United States continuously compounded stock markets returns denominated in terms of the local currency. The sample period extends from April 41988 through to December 132007 . The Lagrange multiplier test is performed with respect to first-order ARCH. The unit root summary statistics are the Philips Perron (PP), the Augmented Dickey Fuller (ADF) and the ADF with Garch (following Seo '99) test statistics respectively; in square brackets find the test statistic for the return of the corresponding market. Adjacent to the square brackets find the test statistic for the stock market levels. When required the lag length is determined by minimising the Bayesian Information Criterion over models with lag lengths 1 to 5 . The superscripts $a, b$ and $c$ indicate significance at the 1 percent, 5 percent and 10 percent levels, respectively. 
Figure 2: Recursive Unit Root Tests: Asian, European and United States stock

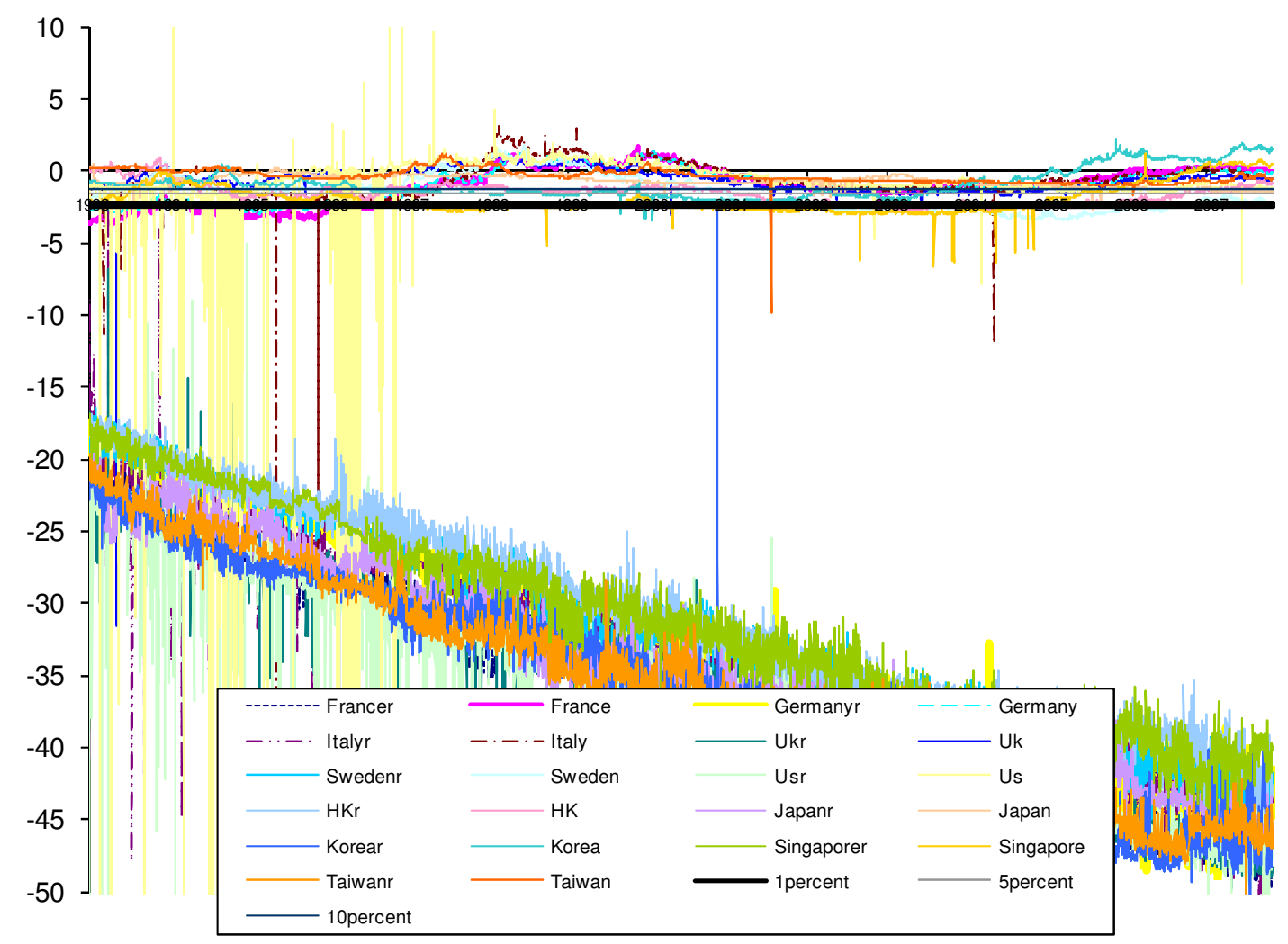

Notes. The unit root summary statistic is the Augmented Dickey Fuller test statistic extended to control for GARCH effects. The critical values are sourced in Seo 1999. The test statistic is performed recursively: initiated during the period April 41988 through to 18 February 1993 and the unit root test is repeated with respect to each extension of the window of data by a single daily observation. The final performance of the test is over the period April 41988 through to 13 December 2007. 
Table 2: Pair-wise Correlations - Asia, Europe and the United States Stock Markets

Europe and US Correlations

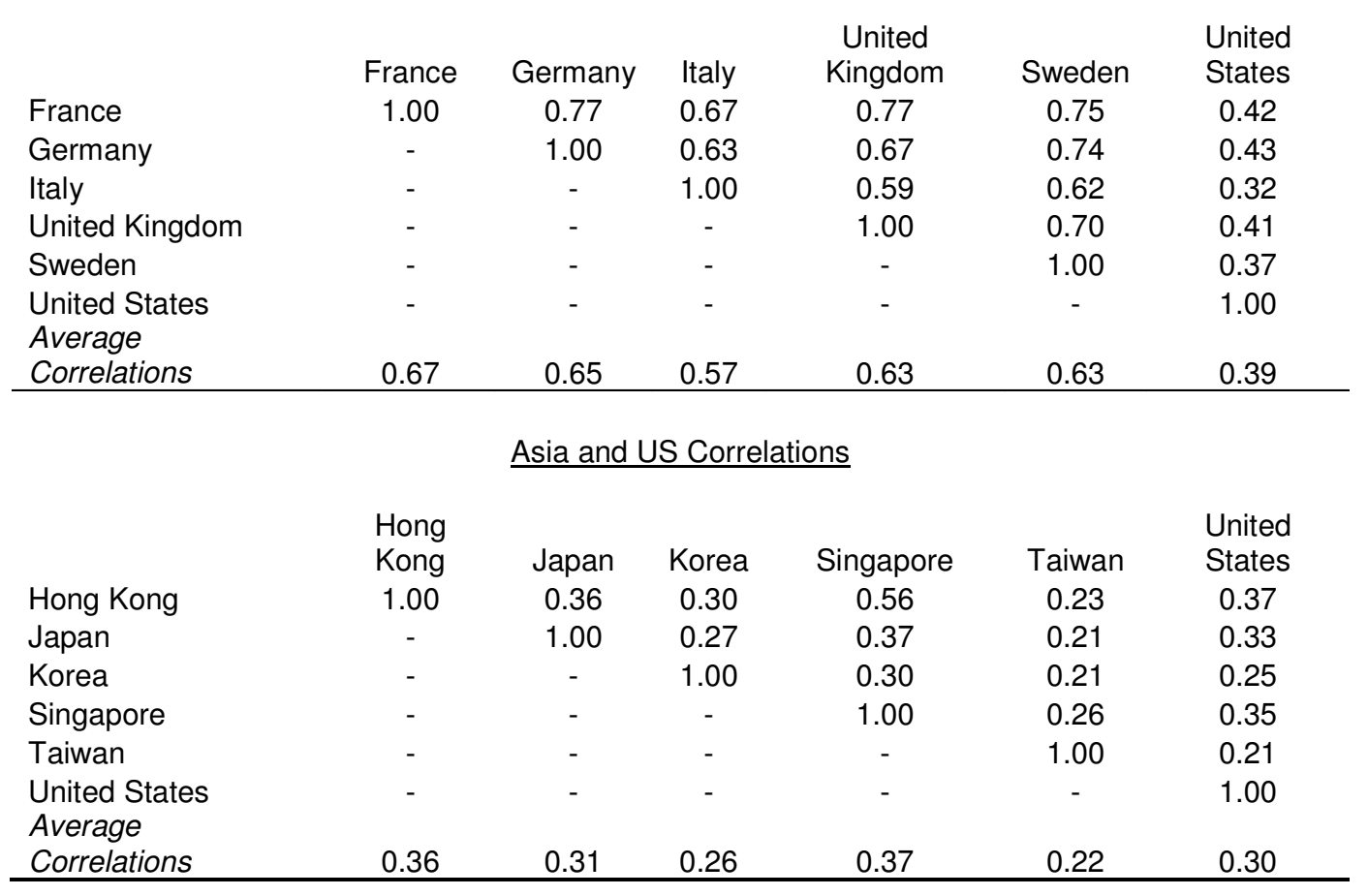

Notes. The Table contains pair-wise correlations concerning the examined Asian, European and United States continuously compounded stock markets returns, denominated in terms of the local currency. The sample period extends from April 41988 through to December 132007. 
Figure 3: Recursive Pair-Wise Unconditional Correlations between the Asian, European and United States Stock Markets

Panel A: Recursive Unconditional Correlations: Asia and the US

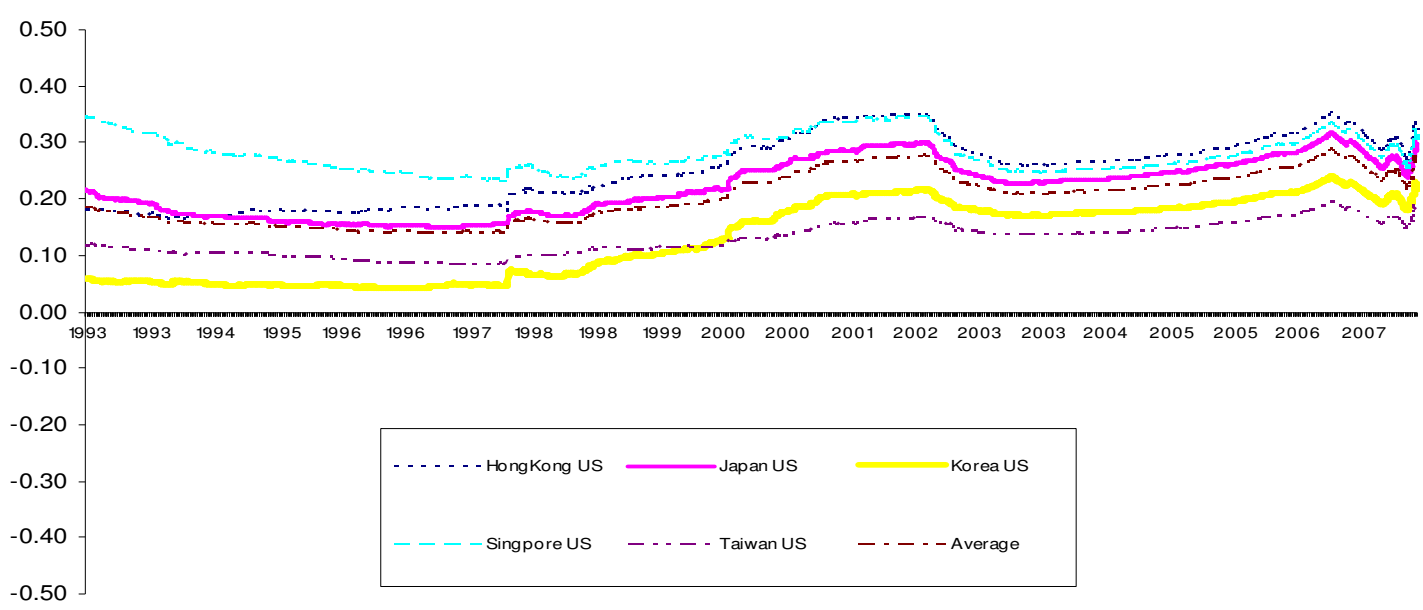

Panel B: Recursive Unconditional Correlations: Europe and the US

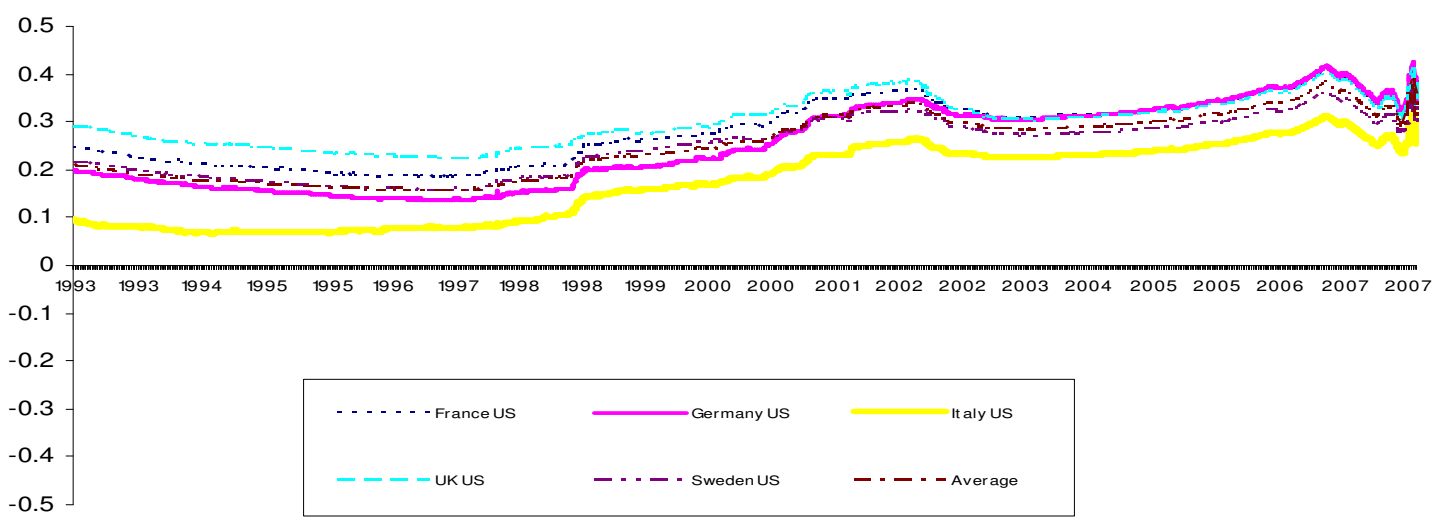

Notes. The Figure contains two Panels. Panel A presents recursively estimated unconditional correlations (controlling for heteroskedasticity), following Forbes and Rigobon (2002), between the Asian stock markets (Hong Kong, Japan, Korea, Singapore and Taiwan) and the United States stock market. Panel B presents results from the same methodology with respect to the European stock markets (France, Germany, Italy, Switzerland and the United Kingdom) and the United States stock market. The initial period of estimation extends from April 41988 through to 4 March 1993 and the test is repeated with respect to each extension of the window of data by a single daily observation. The final estimation window extends to December 132007. 


\section{Table 2 Johansen Multivariate Test for Cointegration}

\begin{tabular}{ccccc} 
Null & Trace & \multicolumn{3}{c}{ Critical values } \\
Hypothesis & & $10 \%$ & $5 \%$ & \multirow{2}{*}{$1 \%$} \\
Panel A: Asian Markets & & & & \\
$\gamma=0$ & $76.53^{\mathrm{c}}$ & 71.86 & 76.07 & 84.45 \\
$\gamma<=1$ & 40.10 & 49.65 & 53.12 & 60.16 \\
$\gamma<=2$ & 22.61 & 32.00 & 34.91 & 41.07 \\
$\gamma<=3$ & 8.22 & 17.85 & 19.96 & 24.60
\end{tabular}

\begin{tabular}{ccccc} 
Null & Trace & \multicolumn{3}{c}{ Critical values } \\
$\begin{array}{c}\text { Hypothesis } \\
\text { Panel C: Asian Markets + US }\end{array}$ & $10 \%$ & $5 \%$ & \\
\cline { 1 - 2 }$\gamma=0$ & $105.78^{\mathrm{b}}$ & 97.87 & 103.68 & 110.15 \\
$\gamma<=1$ & 69.08 & 71.81 & 76.81 & 83.74 \\
$\gamma<=2$ & 44.57 & 49.95 & 53.95 & 56.73 \\
$\gamma<=3$ & 22.53 & 31.93 & 34.07 & 37.78
\end{tabular}

Panel B: European Markets

$\begin{array}{lllll}\gamma=0 & 91.94^{\mathrm{a}} & 71.86 & 76.07 & 84.45 \\ \gamma<=1 & 50.31^{\mathrm{c}} & 49.65 & 53.12 & 60.16 \\ \gamma<=2 & 24.44 & 32.00 & 34.91 & 41.07 \\ \gamma<=3 & 10.21 & 17.85 & 19.96 & 24.60\end{array}$

Panel D: European Markets + US

$\begin{array}{ccccc}\gamma=0 & 136.50^{\mathrm{a}} & 97.87 & 103.68 & 110.15 \\ \gamma<=1 & 83.05^{\mathrm{b}} & 71.81 & 76.81 & 83.74 \\ \gamma<=2 & 50.89^{\mathrm{c}} & 49.95 & 53.95 & 56.73 \\ \gamma<=3 & 24.28 & 31.93 & 34.07 & 37.78\end{array}$

Notes. The Table comprises four Panels - presenting Johansen (1988) Likelihood Ratio Trace test statistics for four sets of markets. Panel A contains a 5stock market set including Hong Kong, Japan, Korea, Singapore and Taiwan. Panel B contains a 5-stock market set containing France, Germany, Italy, the United Kingdom and Sweden. Panels C and D extend these market sets to include the United States market. The data are observed from April 41988 through to December 13 2007. $\gamma$ is the number of cointegrating vectors under the null hypothesis. The lag length of the specification of the corresponding vector error correction model is selected with respect to a Bayesian Information Criterion (over models with lag lengths 1 through 5). This criterion indicates that one lag of returns is included in the estimated vector error correction model. The critical values are simulated or sourced on Table 0 in Osterwald-Lenum (1992). The superscripts a, b and c indicate significance at the 1 percent, 5 percent and 10 percent levels, respectively. 
Table 3 Modified multivariate test for Cointegration with $\operatorname{GARCH}(1,1)$ effects

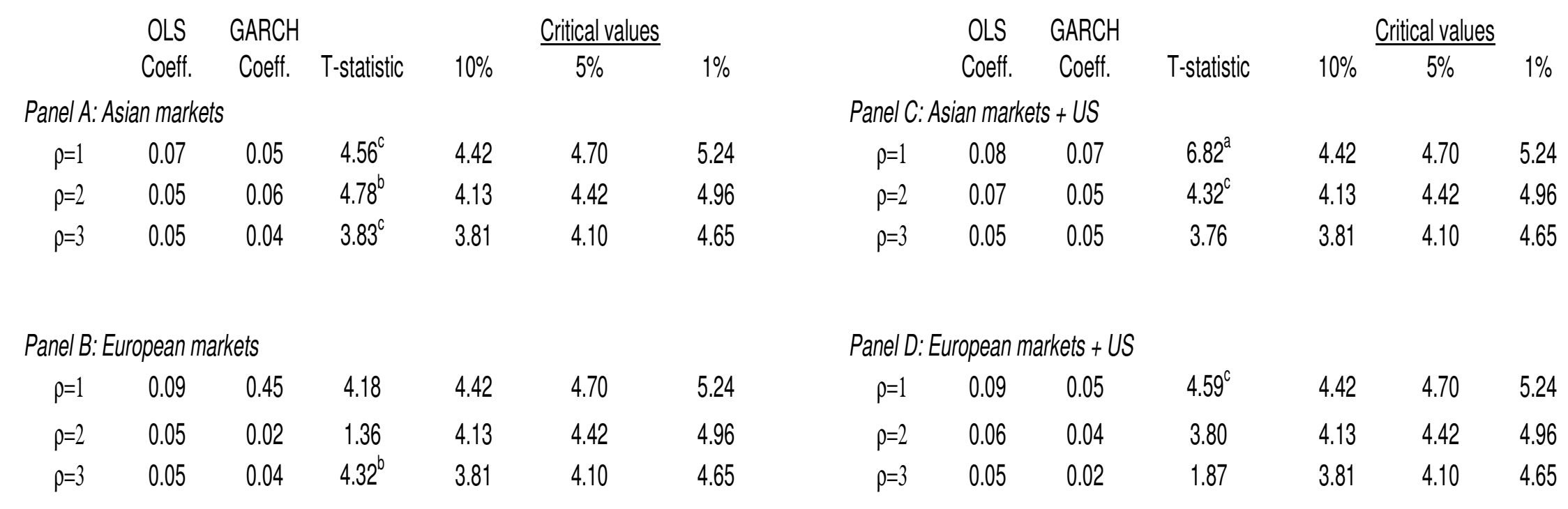

Notes. The Table comprises four Panels. Panels A and B contain Asian and European stock markets denominated in local currency terms, respectively. Panel A contains a 5-stock market set including Hong Kong, Japan, Korea, Singapore and Taiwan. Panel B contains a 5-stock market set containing France, Germany, Italy, United Kingdom and Switzerland. Panels C and D extend the former sets to include the United States market denominated in terms of the United States dollar. The data sets are observed from April 41988 through to December 13 2007. Coefficients for $\rho=1 \ldots 6$ are the estimated square roots of the Eigen values of the Johansen longterm information matrix, accounting for (i.e. GARCH Coeff.) and not accounting for (i.e. OLS Coeff.) t-distributed GARCH effects. The coefficients are estimated using Equations 23-24. The t-statistic critical values are sourced on Table 1 in MacKinnon (1991). The superscripts a, b and c indicate statistical significance at the 1 percent, 5 percent and 10 percent levels, respectively. 
Figure 4: Examining the Null Hypothesis of No Cointegration

Recursive Johansen (1988) Trace Statistics:
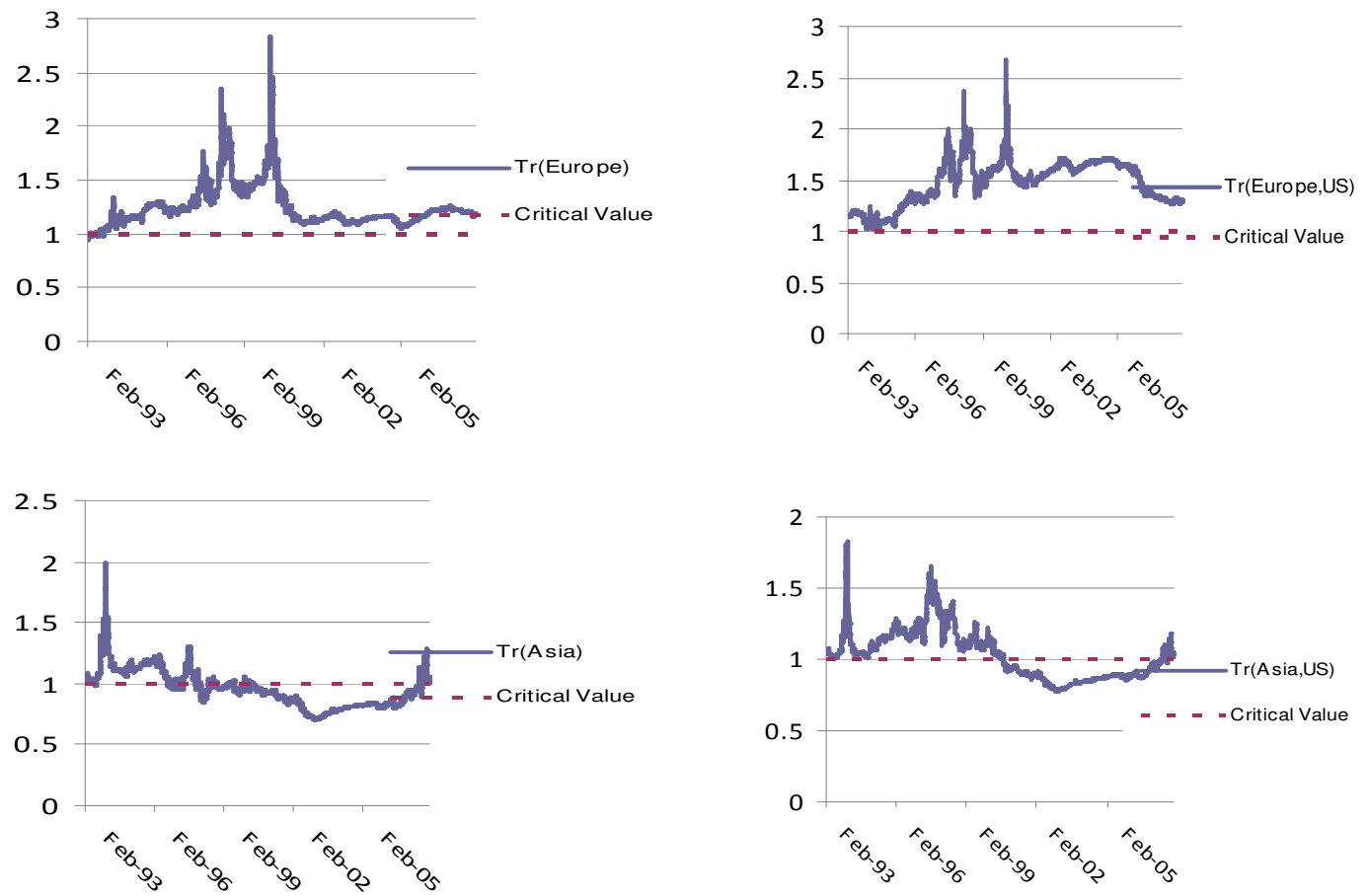

\section{Recursive Gannon (1996) Test Statistics:}


Notes. The Figure presents the recursive test results the Johansen (1988) trace test statistic and the Gannon (1996) test statistic with respect to the null hypothesis of no cointegrating vectors in the Asian and European stock market systems, and in these stock market systems extended to include the United States stock market. The Johansen test results are referenced by means of the letters 'Tr', for Likelihood Ratio Trace statistic, while the Gannon statistics are referenced by means of the letters 'Mod', short for modified Johansen cointegration test. The initial period of estimation extends from April 41988 through to 18 February 1993 and the test is repeated with respect to each extension of the window of data by a single daily observation, through to December 2007. 